\title{
Surgery in the Time of Covid-19: Reflections on a Pandemic
}

\author{
Michael Mwachiro \\ Tenwek Hospital
}

Correspondence to: Dr. Michael Mwachiro; Email: deche2002@yahoo.com

Keywords: Surgery, Covid-19 pandemic

Ann Afr Surg. 2020; 17(2):48-50

DOI: http://dx.doi.org/10.4314/aas.v17i2.1

Conflicts of Interest: None

Funding: None

(C) 2020 Author. This work is licensed under the Creative Commons Attribution 4.0 International License

The world has almost ground to a halt. Not since the influenza pandemic of 1918 has such angst been seen on such a scale. In Africa, we are following keenly the developments within the continent and other parts of the world. The numbers of confirmed cases continue to spike and the epifocus has since shifted from China to Europe and the USA. Concerns are that the next peak in cases may be in Africa.

\section{What do we know so far?}

Covid-19 is caused by a novel coronavirus: severe acute respiratory syndrome coronavirus 2 (SARS-CoV-2) (1). The disease is infectious and is spread by droplets from either saliva, sputum or nasal discharge. The presentations are varied and include fever, fatigue and a raft of respiratory and gastrointestinal symptoms (1-4). Asymptomatic spread can occur in the prodromal phase. Vulnerable populations - such as the elderly and those with medical comorbidity - have a higher risk of developing serious illness if infected. Currently, global recommendations to prevent virus transmission include hygiene measures such as hand washing, reducing droplet transmission and measures to avoid crowding through social distancing, and total or partial lockdowns (5).

Information and research on Covid-19 are ongoing and dynamic as teams study the disease as well as ways to stem the tide. Globally, multiple recommendations have been made on providing surgical services. The consensus is to halt elective procedures and carry out emergency and cancer-related procedures (6-8). The Surgical Society of Kenya has also issued similar recommendations (9).

\section{To operate or not to operate?}

Preparation is key in all scenarios. The American College of Surgeons (ACS) recommends forming a Surgical Review Committee (SRC) that will involve surgery, anesthesia and nursing at the time of decision making (10). In addition, postponing elective procedures is important to reduce patient traffic and conserve hospital resources (11). It is important that non-essential staff are also minimized in hospitals (11).

When surgical procedures are needed in the emergent setting or for other indications such as malignancy where it is impossible to postpone, then special care must be taken. Personal Protective Equipment (PPE) must be worn and universal precautions taken to ensure the surgical team is not compromised. An N95 mask has been proven to protect the wearer by filtering very small particles and is recommended. Full PPE has been recommended in general anesthesia procedures and also for all emergent endoscopic procedures as they are aerosol-generating procedures (AGP) (8). Appropriate use of suctioning is key in procedures using diathermy. In addition, endoscopic procedures require close proximity to patients, and such would pose a great risk (12). Surgical masks can be used in the appropriate settings.

Personnel in the operating room must be familiar with appropriate use of PPE as well as in donning and doffing processes. Setting up a dedicated operating area will limit the spread of the disease (11). Anesthesia and airway-related procedures require use of full PPE as they are also AGP with high risk (12). These recommendations also extend to laparoscopy, cardiopulmonary resuscitations and laryngoscopy. Appropriate precautions are to be taken for all staff and the operating room workflow maintained in such 
a manner to minimize risk. Similarly, ventilators should be set aside for procedures on patients with Covid-19 (13). Risk stratification is important for non-emergent procedures that need to be carried out (3).

\section{The teaching dilemma}

As systems struggle to grapple with the ongoing crisis, one of the core pillars of surgery - training - has also been affected. Trainers world over are grappling with this issue. As the call to cancel elective cases continues to echo, it comes with reduced case volumes. To compensate for this, there have been recommendations to make hardship adjustments to these case volume requirements (13). In addition, most facilities are also reducing numbers of personnel that congregate even at the workplace and this comes with challenges in traditional teaching setups. Keeping all personnel safe is our top-most priority at all times. All trainees must be well trained in appropriate donning and doffing techniques for PPE (13). In addition, it is imperative that senior surgeons and trainers always look out for the safety of trainees at all steps of the procedure. Similar to the military, consultants should not expect or ask trainees to do anything the senior surgeons will not do.

Restructuring surgical learning has been advocated (13). In the African setup, the flipped classroom model has already been adopted in collegiate training with the College of Surgeons of East, Central and Southern Africa (COSECSA) where online modules are being provided for both junior and senior trainees. The actual learner and trainer interactions can also be navigated creatively with smaller groups and with use of online platforms where necessary. Some universities have adopted the use of online multimedia platforms for most didactic lessons and demonstrations of procedures and skills. If possible, trainees should be protected as much as possible and especially when carrying out procedures on Covid-19 patients (11). This may mean limiting participation in cases of Covid-19 patients. However, if there are personnel constraints, their services can be allowed judiciously and with strict attention to use of PPE. The reality in our setup is that trainee surgeons are a critical part in provision of surgical care across the continent and thus are needed to augment care for patients. Other measures that have been suggested include having trainees and trainers adopt "on call" strategies to minimize exposure and maximize efficiency (9). When this pandemic passes, further restructuring will be needed as surgical teaching is restored to normalcy (13).
Maintaining sanity amid the crisis: The intertwine of surgery, economics and governance

Surgeons inhabit an ecosystem where the stakes are high. Indeed, decisions must be made each day and many may have significant ramifications to both patient and surgeon. This global crisis comes with its own set of challenges. The mental and emotional strain can also be debilitating. Some aspects are within our control—such as knowledge of use of PPE or choice of whether to carry out the operation. However, many aspects are not in our control such as provision of PPE equipment by the government or presence of supplies. Such deficits increase the stress coefficient on healthcare workers. In addition, restrictions of movement by curfews and lockdowns affect these teams as they may be in hospitals longer and face challenges accessing food and other essential supplies at odd hours. Employers and governments have a responsibility to ensure that frontline workers have access to PPE and relevant supplies. Surgical teams and other frontline workers must be conversant with government guidelines, relevant protocols and appropriate knowledge of use of PPE (14).

The immense personal risk that health workers are exposed to, and the isolation that comes with working in Covid-19 zones add to the mental stress. Reports from other parts of the world show that many health workers have been infected; this in itself makes Covid-19 a formidable disease to treat (15). The elephant in the room, especially in our setup, is what happens when a health worker gets debilitated from contracting Covid-19 or, even worse, succumbs to it? Currently, there is no compensation for frontline workers in case this happens, a significant reason why workers are hesitant to respond when called upon (16). These discussions are urgent even as we set up isolation units and put in place other preventive measures. According to WHO, frontline workers have a provision to withdraw if they feel inadequately protected or prepared (14). This poses questions in areas where already a low patient to surgeon or physician ratio exists. It is thus important to have transparent communication within teams and also multidisciplinary discussions with frontline workers (15). This will contribute to trust and better self-care among teams (17).

Covid-19 has inadvertently exposed the thin veneer that had been used to paper over the cracks in the healthcare systems in many parts of Africa. Healthcare has been the underappreciated third musketeer when compared with security and education. It is not all gloom; this crisis has also brought out the innovative and collaborative side of humanity. Hopefully, when this tide passes, we shall have 
also found lasting healthcare solutions and upgrades to our infrastructure.

The government is doing its part as it has introduced a raft of measures that need all hands on the deck (17). Hopefully, these measures will flatten the curve in Africa, if we abide by them. It is thus imperative that we use this window to prepare through repurposing manufacturing industries to provide local solutions and using the informal sector to help bridge the gap.

Teamwork is paramount. We are all part of the healthcare response team. We should all take care to protect ourselves, our colleagues, our patients, our families. As surgeons, we are used to the efficiencies of teamwork. This is precisely what is needed to beat the novel coronavirus together.

\section{References}

1. National Center for Immunization and Respiratory Diseases (NCIRD), Division of Viral Diseases. https://www.cdc.gov/ncird/index.html. Accessed 29th March 2020.

2. Chen N, Zhou M, Dong X, Qu J, Gong F, et al. Epidemiological and clinical characteristics of 99 cases of 2019 novel coronavirus pneumonia in Wuhan, China: a descriptive study. The Lancet. 2020; 395(10223):507-13.

3. Chan JF, Yuan S, Kok KH, To KK, et al. A familial cluster of pneumonia associated with the 2019 novel coronavirus indicating person-to-person transmission: a study of a family cluster. The Lancet. 2020 Feb 15;395(10223):514-23.

4. Repici A, Maselli R, Colombo M, Gabbiadini R, Spadaccini M, Anderloni A, Carrara S, Fugazza A, Di Leo M, Galtieri PA, Pellegatta G. Coronavirus (COVID-19) outbreak: what the department of endoscopy should know. Gastrointestinal endoscopy. 2020 Mar 14.

5. Coronavirus disease (COVID-19) pandemic. World Health Organization. https://www.who.int/emergencies/diseases/novelcoronavirus-2019 Accessed 29th March 2020.

6. COVID-19: Recommendations for Management of Elective Surgical Procedures. https://www.facs.org/covid-19/clinical-guidance/elective-surgery Accessed 29th March 2020.
7. Intercollegiate General Surgery Guidance on COVID-19 UPDATE. https://www.rcsed.ac.uk/news-public-af-

fairs/news/2020/march/intercollegiate-general-surgery guidanceon-covid-19-update. Accessed 29th March 2020.

8. COVID-19: Elective Case Triage Guidelines for Surgical Care. https://www.facs.org/covid-19/clinical-guidance/elective-case Accessed 29 March 2020.

9. COVID-19: SSK statement on recommendations for surgical procedures and outpatient clinics. https://www.ssk.or.ke/covid-19/ Accessed 29th March 2020.

10. Create a Surgical Review Committee for COVID-19-Related Surgical Triage Decision Making. Developed by the American College of Surgeons, American Society of Anesthesiologists, and Association of Peri-Operative Registered Nurses.

https://www.facs.org/covid-19/clinical-guidance/review-committee

11. Brindle ME, Gawande A. Managing COVID-19 in surgical systems. Ann Surg. 2020. 67s, 0372354.

12. Ti, LK, Ang, LS, Foong, TW, et al. What we do when a COVID19 patient needs an operation: Operating room preparation and guidance. Can J Anesth/J Can Anesth (2020).

13. Daodu O, Panda N, Lopushinsky S, et al. COVID-19 - Considerations and implications for surgical learners. Ann Surg, 2020. Manuscript in press.

14. World Health Organization. Coronavirus disease (COVID-19) outbreak: Rights, roles and responsibilities of health workers, including key considerations for occupational safety and health. Interim guidance. 19 March 2020. https://www.who.int/publications-detail/coronavirus-disease-(covid-19)-outbreak-rights-rolesand-responsibilities-of-health-workers-including-key-considerations-for-occupational-safety-and-healthWHO/2019nCov/HCW_advice/2020.2

15. $\mathrm{Ng} \mathrm{K}$, Poon BH, KiatPuar TH, et al. COVID-19 and the risk to healthcare workers: A case report. Ann Intern Med. 2020; [Epub ahead of print 16 March 2020]

16. Concerns over death-in-service benefits keeping doctors from NHS frontline. https://www.theguardian.com/society/2020/mar/29/concerns-over-death-in-service-benefits-keeping-doctors-from-nhs-frontline Accessed 29 March 2020

17. Ministry of Health: General Information on Coronavirus Disease 2019. http://www.health.go.ke/wp-content/uploads/2020/03/General-information-about-COVID-19.pdf 